\title{
No generation effect without semantic activation
}

\author{
ROBERT M. SOLOWAY \\ Emory University, Atlanta, Georgia
}

\author{
(Eugene Winograd, Sponsor)
}

\begin{abstract}
Previous studies have demonstrated a memorial advantage for self-generated words when compared with these same words when they have been read (generation effect). The present study attempted to discover whether this memorial advantage would still occur if the self-generated items were retrieved from short-term memory instead of from long-term memory, as is customary. Findings replicated the usual generation effect, but no generation effect was found from shortterm memory. This result is consistent with an explanation of the generation effect's being due to semantic activation in long-term memory.
\end{abstract}

In 1978, Slamecka and Graf reported a series of studies delineating a phenomenon they called the generation effect. Basically, their findings demonstrated that memory for self-generated verbal items is superior to memory for those same verbal items after the subject has only read them. For example, in Slamecka and Graf's experiment, subjects either were presented with the opposite pair hot-cold or were presented with hot-c_ _ and asked to generate the appropriate antonym. Subsequent memory tests demonstrated enhanced recall and recognition for the words that the subjects had generated. Further research has demonstrated the effect within sentences (Ghatala, 1981; McFarland, Frey, \& Rhodes, 1980) and with numerics (Gardiner \& Rowley, 1984; Russo \& Wisher, 1976). The effect has failed to be obtained for nonwords (McElroy \& Slamecka, 1982), for bigrams (Schwartz, 1971), for meaningful sentences (Ghatala, 1981), and for anomalous sentences (Graf, 1980).

The explanation of the generation effect tested here is the semantic activation hypothesis. This hypothesis states that the act of generating results in greater semantic activation than does the act of reading. In other words, the act of generating requires the subject to create stronger bonds within that item's semantic network, hence improving its retrievability. Researchers who support the semantic activation position argue that generating meaningless material does not show a memorial benefit because preexisting semantic information is not activated. The results of McElroy and Slamecka's (1982) and Graf's (1980) studies, showing no generation effect for nonwords and anomalous sentences, support this assertion. Further support for the semantic activation hypothesis comes from studies demonstrating an effect in situations in which generation has been attempted but has failed (Kane \& Anderson, 1978; Slamecka \& Fevreiski, 1983). The semantic activation theory claims that the attempt to generate a word

I gratefully acknowledge the assistance and sponsorship of Eugene Winograd. Requests for reprints should be sent to Robert Soloway, Department of Psychology, Emory University, Atlanta, GA 30322. activates a semantic network whether or not the target word is successfully retrieved.

To investigate the necessity of semantic activation for the generation effect, a study was conducted to look at the memorial consequences of generating from short-term memory (STM). Jacoby (1978) noted that when the task of generating was trivialized by providing the correct response immediately prior to the question, no generation effect was found. The purpose of the present experiment was to replicate these findings and to provide a generation task from STM which was not trivial. The task utilized in the present study provided subjects with words that had to be committed to memory for a period of $15 \mathrm{sec}$. However, neither reason nor time to elaboratively rehearse the words was provided. At the time of the generation task, subjects in this condition were required to retrieve the recently studied words. Since no clues other than the first letter of the target were provided at this time, subjects had no alternative but to retain the words from their initial reading. It was assumed that this would minimize semantic activation and require retrieval from STM. Therefore, it was hypothesized that evidence of a generation effect for the group generating words from STM would be damaging to a semantic activation account.

\section{METHOD}

\section{Subjects}

Subjects were 106 Emory University undergraduates participating for course credit. Subjects were tested in groups of between 7 and 19. The number of subjects in each of the four conditions ranged from 25 to 30 .

\section{Materials}

A list of 40 word pairs was constructed containing 20 antonym pairs and 20 synonym pairs. The pairs were selected so as not to be composed of the most obvious antonym or synonym pairs but also so as not to be very difficult (e.g., near-far). The list was divided into eight blocks of 5 pairs each. A given block was either all antonyms or all synonyms. One word order was used for all conditions.

\footnotetext{
Procedure

All word pairs were read aloud to the subjects in blocks of five. The subjects were informed, before each block of associates, whether they
} 
were about to hear antonyms or synonyms. Subjects in the write group were read the intact pairs of words and were asked to write down the second word from each pair. Three seconds after reading the pair, the second word of the pair was repeated (e.g., "near-far...far"). If subjects were unable to write the second word until its repeated presentation, they were instructed to indent it slightly on the page. This was demonstrated to them. The generate group was read the first word in each pair and the first letter of the second word. They were told to write down the antonym or synonym that completed that pair. In all cases, the correct response was read $3 \mathrm{sec}$ later (e.g., "near-f_...far." The subjects were told that if they had been unable to generate the answer at the appropriate time, they should write it when it was presented $3 \mathrm{sec}$ later, but that they should indent it slightly. The trivial-generate group was read the same material as the generate group, but with one important alteration: they were read the correct response $3 \mathrm{sec}$ prior to the word pair instead of $3 \mathrm{sec}$ after (e.g., "far ... near-f__"). Subjects were told not to write the response word until they had heard the stimulus word and the first letter of the correct response. The generatefrom-STM group was read an entire block of five pairs. This group was told to remember the second word from each pair and to write it down when they heard the first letter of that word. The reading of first letters immediately followed each block of pairs. In other words, these subjects heard five pairs, followed by five letters that corresponded to the first letter of the second word from each pair (e.g., "near-far... lifedeath ...early-late ... work-play ... shut-open ...f ...d...l...p... $o \ldots$..'). These subjects had no alternative but to recall the second word from each pair from STM in order to perform appropriately on the generation task. Immediately following the writing of the last word from the last block, all subjects were instructed to turn over their papers and write down as many of the target words as they could recall.

\section{RESULTS AND DISCUSSION}

Means for free recall scores are as follows: 9.88 for the write group, 12.52 for the generate group, 8.37 for the trivial-generate group, and 10.73 for the generatefrom-STM group. A one-way analysis of variance yielded $F(3)=8.53, p<.001$. Between each of the pairs of groups, $t$ values revealed that recall scores for the generate group were significantly better than for each of the other groups $(p<.05)$. The generate-from-STM group proved to be significantly better than the trivial-generate group. All other comparisons were nonsignificant.

The fact that the generate group demonstrated a recall advantage over the write and generate-from-STM groups supports a theory of semantic activation. The finding that the generate-from-STM group demonstrated superior recall over the trivial-generate group probably only indicates the absurdity of the trivial task. Generation failures accounted for $11.2 \%$ and $6.1 \%$ of the responses of the generate and generate-from-STM groups, respectively. Since there were no recall differences within groups between those subjects exhibiting a high rate of generation failures and those exhibiting a lower rate of failures, this factor was not considered further.

The major finding therefore supports a semantic activation theory of the generation effect. Since both the generate-from-STM and the generate groups had to perform acts of retrieval to solve the generation task, the difference between them was only in the locale of processing. In order to solve the generation task, the generatefrom-STM group was retrieving from an episodic event occurring only seconds before, whereas the generate group was retrieving the words from semantic store. Later, at the time of final recall, the generate-from-STM group was now required to retrieve the words from longterm memory. Meanwhile, the generate group was reretrieving the words from long-term store. Apparently there were benefits gained from the initial activation of those words. This advantage is precisely what a semantic activation theory would predict.

\section{REFERENCES}

Gardiner, J. M., \& Rowley, J. M. (1984). A generation effect with numbers rather than words. Memory \& Cognition, 12, 443-445.

Ghatala, E. S. (1981). The effect of internal generation of information on memory performance. American Journal of Psychology, 94, 443-450.

GraF, P. (1980). Two consequences of generating: Increased inter- and intraword organization of sentences. Journal of Verbal Learning \& Verbal Behavior, 19, 316-327.

JACOBY, L. L. (1978). On interpreting the effects of repetition: Solving a problem versus remembering a solution. Journal of Verbal Learning \& Verbal Behavior, 17, 649-667.

KANE, J. H., \& ANDERSON, R. C. (1978). Depth of processing and interference effects in the learning and remembering of sentences. Journal of Educational Psychology, 70, 626-635.

McElroy, L. A., \& SLAMECKA, N. J. (1982). Memorial consequences of generating nonwords: Implications for semantic-memory interpretations of the generation effect. Journal of Verbal Learning \& Verbal Behavior, 21, 249-259.

McFarland, C. E., JR., Frey, T. J., \& Rhodes, D. D. (1980). Retrieval of internally versus externally generated words in episodic memory. Journal of Verbal Learning \& Verbal Behavior, 19, 210-225.

Russo, J. E., \& WiSHER, R. A. (1976). Reprocessing as a recognition cue. Memory \& Cognition, 4, 683-689.

SCHWARTZ, M. (1971). Subject-generated versus experimenter-supplied mediators in paired-associate learning. Journal of Experimental Psychology, 87, 389-395.

Slamecka, N. J., \& GRAF, P. (1978). The generation effect: Delineation of a phenomenon. Journal of Experimental Psychology: Human Learning \& Memory, 4, 592-604.

SLAMECKa, N. J., \& FEVReISKI, J. (1983). The generation effect when generation fails. Journal of Verbal Learning \& Verbal Behavior, 22, 153-163.

(Manuscript received for publication March 19, 1986.) 